\title{
Da urgência de reformular o nada para um mundo pós-capitalista
}

\author{
CLÁUDIA GALHÓS
}

Título: Triste in English from Spanish. Concepção, direcção artística e escrita: Sónia Baptista. Co-criação e interpretação: Ana Libório, Carolina Campos, Cleo Tavares, Joana Levi, Márcia Lança. Espaço cénico: Raquel Melgue. Música original: Sonja. Filme Super-8: Aya Koretzky. Vídeo: Héloise Màrechal. Desenho de luz: Daniel Worm. Figurinos: Lara Torres. Produção: AADK. Co-produção: Culturgest. Local e data de estreia: Culturgest, Lisboa, 24 de Novembro de 2017.

Título: Documentário. Direcção artística e coreografia: Joclécio Azevedo. Colaboração/cenografia: Paulo Mendes. Colaboração/música: Pedro Tudela. Interpretação: Ana Moreira, Dori Negro, Joclécio Azevedo, Pedro Prazeres, Ana Isabel Castro, Rocio Dominguez. Figurinos: Jordann Santos. Desenho e operação de luz: Miguel Carneiro. Produção executiva: Sofia Reis. Filmagem e edição de vídeos: Sofia Arriscado. Fotografia: Susana Neves. Co-produção: Teatro Municipal do Porto. Local e data de estreia: Festival DDD - Dias da Dança, Teatro Campo Alegre, Porto, 11 de Maio de 2018.

Triste in English from Spanish, de Sónia Baptista, e Documentário, de Joclécio Azevedo, são as duas peças de que se fala aqui. Não se trata de assinalar pontos de ligação evidentes entre os dois artistas, de procurá-los, menos ainda de os forçar. Trata-se de articular o devido valor de dois criadores de uma geração próxima - surgidos na transição entre os anos 90 e o novo século -, que têm vindo a criar dentro de uma lógica artística e autoral das artes performativas (muito próxima das artes visuais em ambos os casos e com forte presença da palavra, seja no caso da escrita poética de Sónia Baptista, seja na produção de pensamento e reflexão sobre a própria obra de Joclécio). Acima de tudo, são criadores que têm mantido uma forte coerência no seu trabalho, alheios a tendências ou movimentos agregadores de gostos mais ou menos transitórios. Nesse gesto chegam a pôr-se à margem das modas, reclamando um lugar de identidade fundado em valores substantivos, por isso mais discretos, frágeis, poéticos, problematizadores da arte e da vida.

Com Triste in English from Spanish, de Sónia Baptista, entramos num mundo que convoca a dimensão poética e o contar histórias, mesmo se 


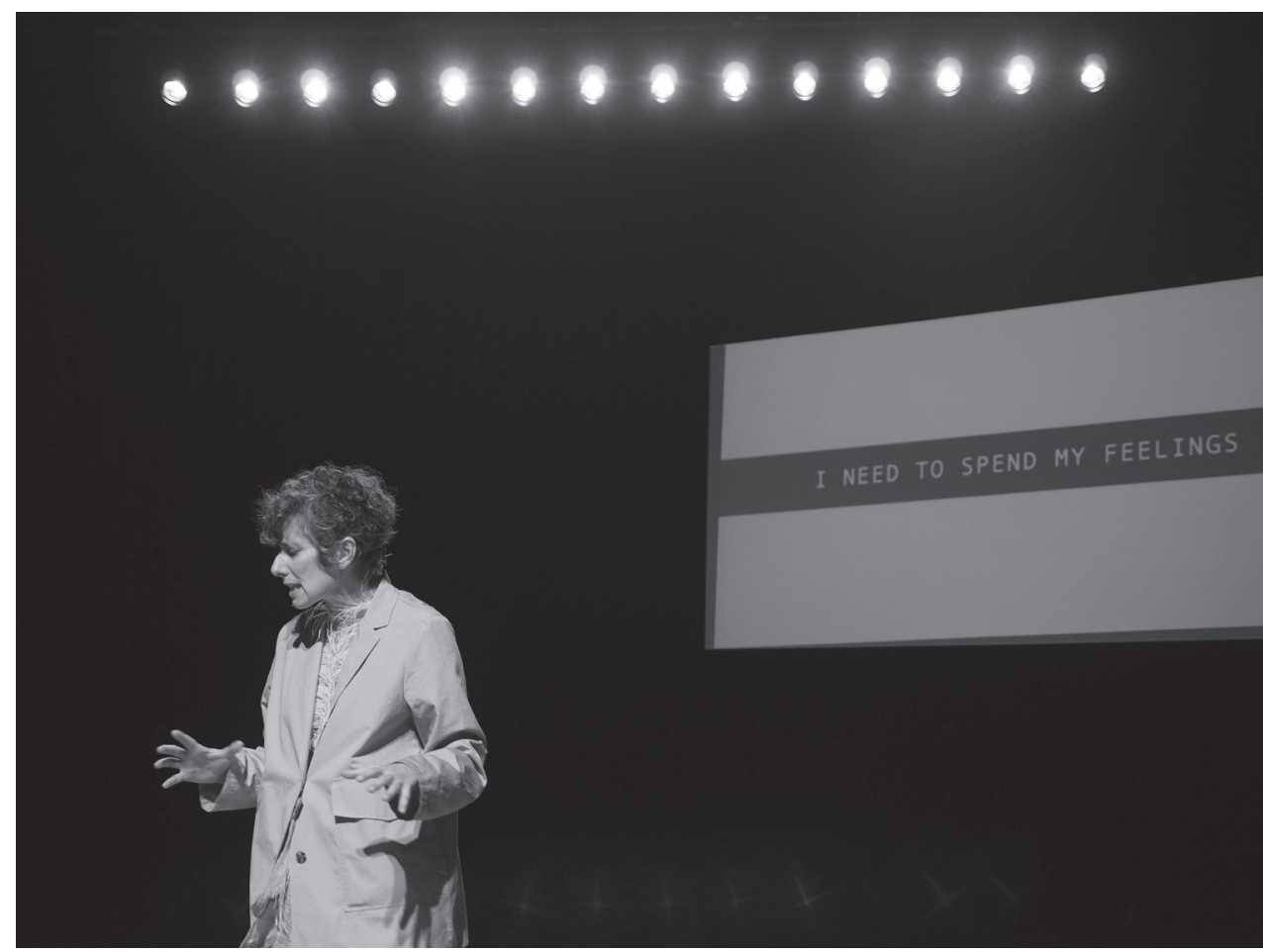

TRISTE IN ENGLISH FROM SPANISH, DE SÓNIA BAPTISTA, CULTURGEST, 2017 (SÓNIA BAPTISTA),

num caminho que se autonomiza dos dois géneros e cria um outro, próprio, específico, que também referencia a conferência e faz amplo uso do powerpoint. No cosmo de Sónia, desde as primeiras criações - com as performances-haikus com que se destacou nos anos $2000^{-}$, a defesa ecológica surgiu naturalmente, numa cosmologia em que os animais são frequentemente figuras relevantes nas narrativas (se não mesmo centrais) e, nesse sentido, competem no protagonismo com a própria criadora, que trabalha numa fronteira frágil entre a narrativa na primeira pessoa $\mathrm{e}$ o evocar as histórias de outros.

É curioso verificar que o diálogo, de conflito mas também humor, que estabelece com uma identidade desdobrada de si em Triste in English... se materializa num urso, que tem tanto de irritante, implicador, rebelde, quanto de ternura e profunda confiança. Esta outra entidade surge como expressão em alter-ego da própria Sónia no diálogo consigo própria, dando carácter temperamental aos estados de melancolia de que fala na peça. O urso (Paula Sá Nogueira) é um lugar de infância, do peluche, da inocência, mas é também o lugar do selvagem, do indomado, da natureza, 


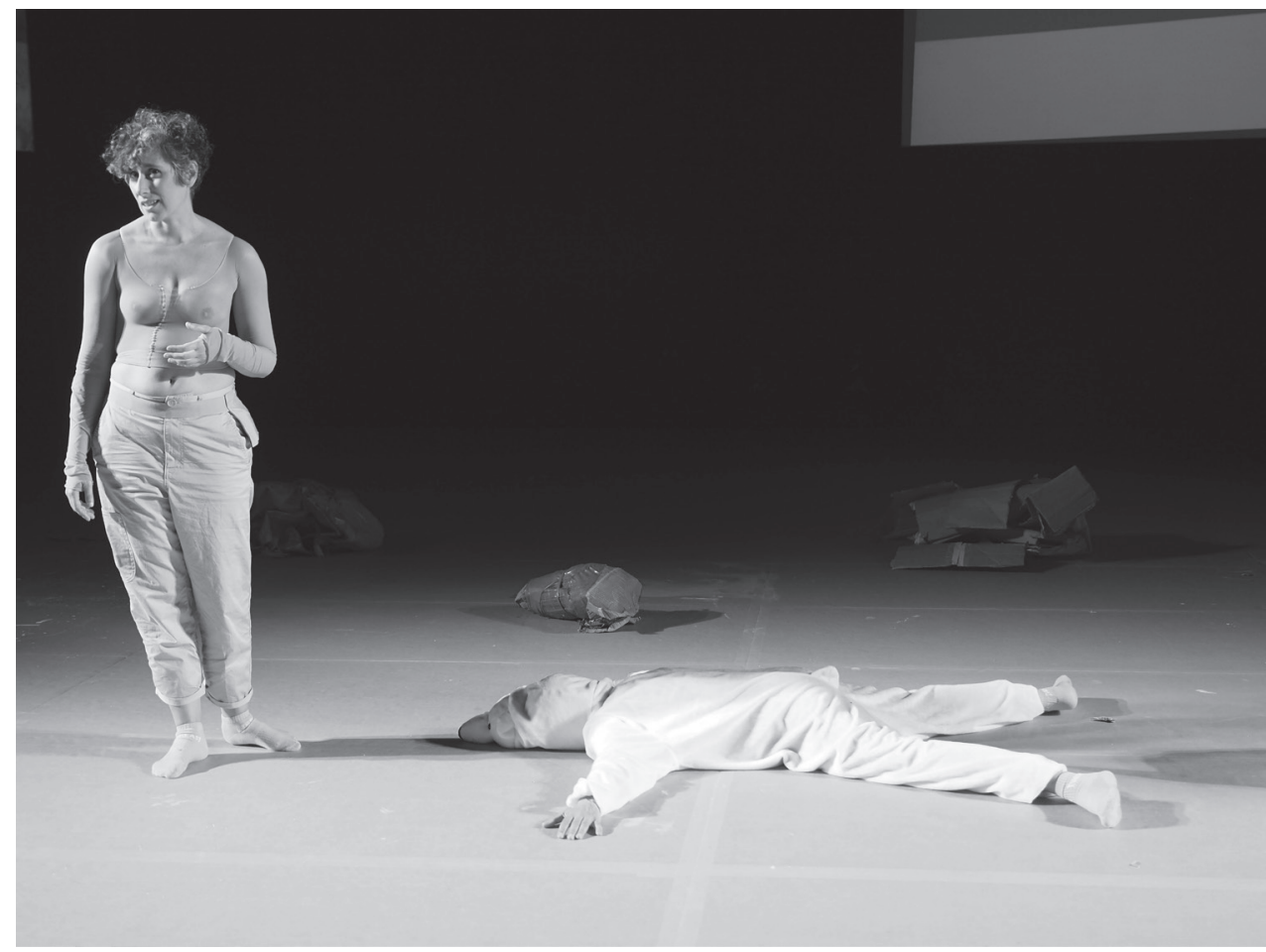

TRISTE IN ENGLISH FROM SPANISH, DE SÓNIA BAPTISTA, CULTURGEST, 2017 (SÓNIA BAPTISTA E PAULA SÁ NOGUEIRA), [F] JOANA DILÃO

do animal. Este lugar é uma circunstância do ser no mundo, relacional e de múltipla influência, de que Sónia não abdica nos seus espectáculos. Daí que repetidamente, nas suas peças e poesias, surja esta associação de nivelamento «desierarquizado» entre a terra, os animais e a mulher, identificando-os como comodidades, objectos ao serviço de ser explorados e assim remetidos para o fim da escala do poder.

A problematização do mundo em que vivemos, a diferentes escalas, de que fazem parte o feminismo ou as matérias vitais, surge com força e presença performativa em Triste in English..., de forma evidente nos momentos em que mais cinco intérpretes (as co-criadoras Ana Libório, Carolina Campos, Cleo Tavares, Joana Levi e Márcia Lança) se juntam a Sónia em cena, numa espécie de quadros de variedades muito próximos de um intervalo do espectáculo. Esta espécie de divertissement parece interromper a linha discursiva anteriormente instalada, propondo pequenos desvios para acções que vão do canto à dança, passam pela pintura «bruta» do corpo feminino em telas, ou pela manipulação de grandes caixotes de papelão que nessa batalha com cada intérprete ganham 


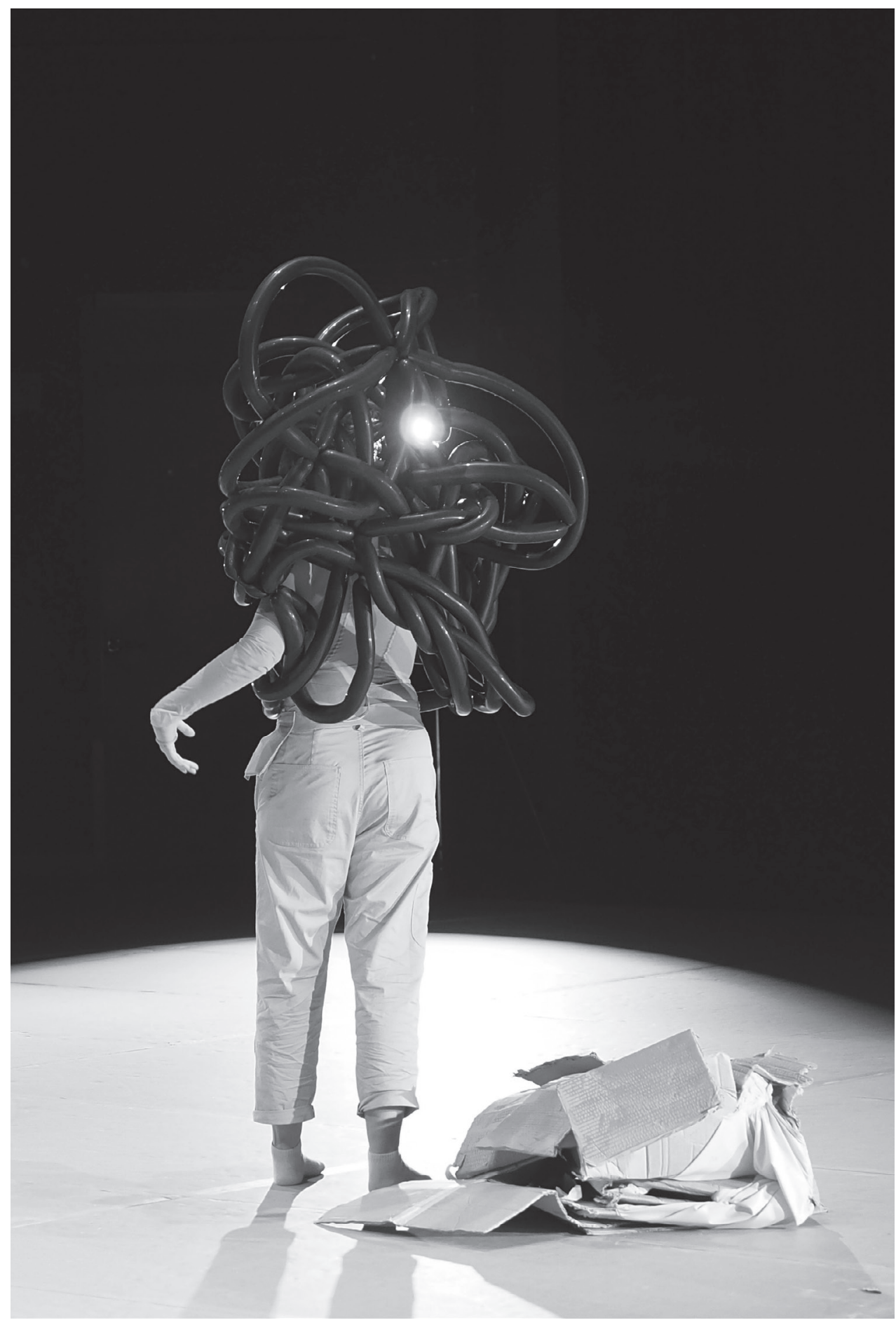

TRISTE IN ENGLISH FROM SPANISH, DE SÓNIA BAPTISTA, CULTURGEST, 2017 (SÓNIA BAPTISTA), [F] JOANA DILÃO 
novas formas escultóricas... Numa conversa a propósito da estreia da peça, Sónia propunha alguns termos por si inventados para nomear o que ali cria: peça «ecosófica» de «psicopoética do browser», que revela toda uma vivência virtual-real e põe a descoberto modalidades de escrita colaborativa dos seus textos, que passaram pela participação de outras pessoas, todas mulheres, mas também no recurso à pesquisa na internet. É aí que encontra aquela que partilha como «a canção mais triste do mundo», ou é nessa esquizofrenia que as línguas também se misturam e recombinam, numa nova dinâmica vocabular e de exercício de plasticidade dos significados gerados por combinações delirantes de palavras de línguas distintas - por exemplo: "II need to spend my feelings."/ Como se dice?/ Preciso de gastar os sentimentos./ E depois fico com o armário cheio./ "These seasons of mental winter." / Como se dice?/ Estas estações de inverno mental.»

Dizia Sónia que «esta vivência antropocêntrica se tornou muito importante para reflectir sobre o meu estado, o estado do mundo que é espelhado no meu estado ou vice-versa. Não sei bem quem/o-quê espelha quem/o-quê, se sou eu quem espelha o mundo, se é o mundo que me espelha a mim. Daí também partir de um discurso muito pessoal sobre a minha tristeza, melancolia, depressão, sobre as três ao mesmo tempo, para espelhar o mundo, para me espelhar a mim própria, para perguntar coisas». Esta formulação vai sendo suscitada ao longo do espectáculo, na qualidade crua das acções que as intérpretes executam e no vínculo material que é gerado pela implicação dos corpos, cuja interacção com outros materiais gera esculturas que são restos, rastos, traços, de permanente metamorfose. Estas acções remetem para um tempo em que a criação performativa tinha implicações políticas e sociais, reivindicando uma certa consciência do mundo, que de modo diverso tem ressurgido nas artes performativas hoje, mas que nunca abandonou o corpo artístico de Sónia Baptista.

É com uma aparente leveza, e muito humor, que aborda problemáticas sérias, algumas experienciadas à escala pessoal, seja nos temas (como a vivência da tristeza, as alterações climáticas, a igualdade/desigualdade de géneros), seja nas questões formais e modalidades discursivas da própria arte (o trânsito entre o tom confessional, o recurso mais «teatral» de diálogo e de construção de ilusão, o formalismo da conferência, com demonstrações e validações visuais do que é dito em projecção de vídeo, ou o corpo manifesto que produz reconfigurações plásticas do real, pelo body painting, dança ou manipulação de cartão). Mas talvez o 


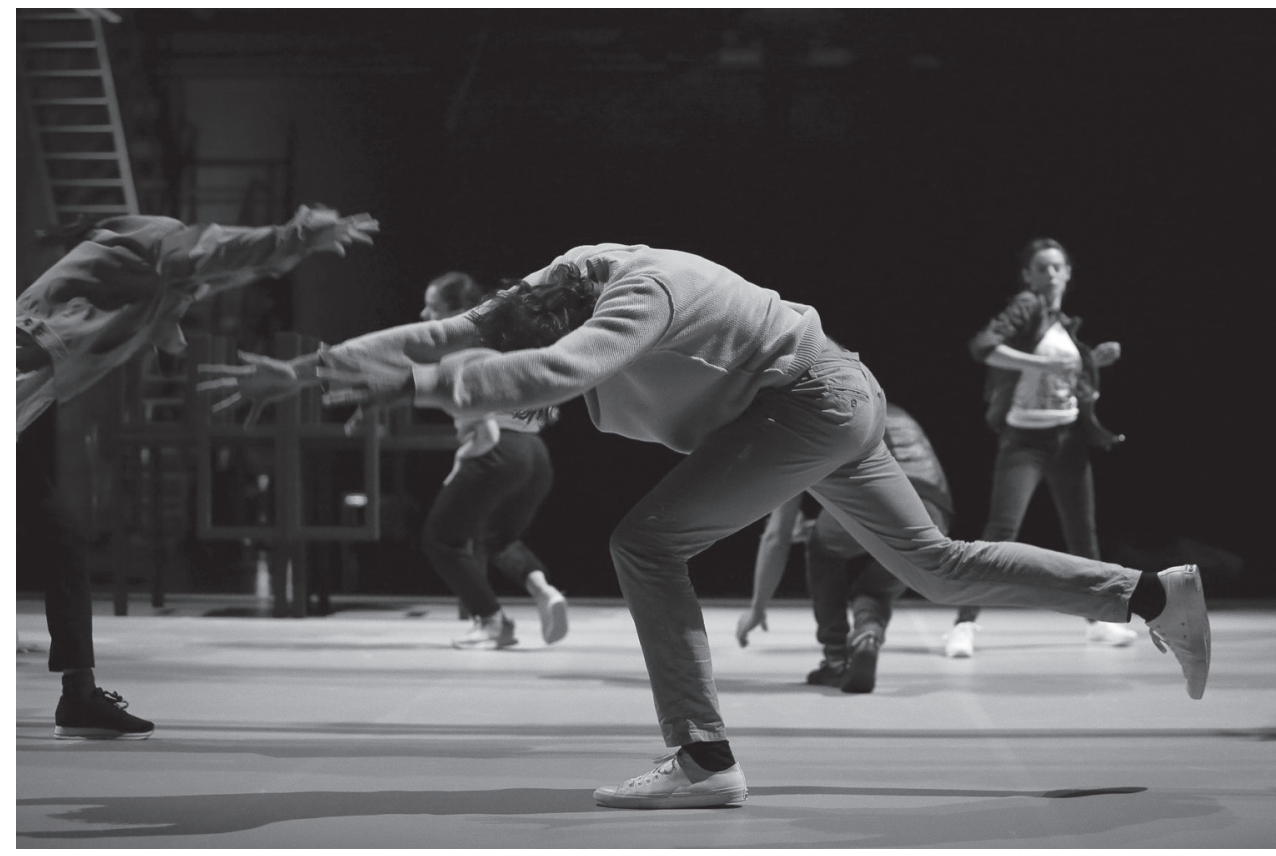

DOCUMENTÁRIO, DE JOCLÉCIO AZEVEDO, TEATRO MUNICIPAL DO PORTO - TEATRO CAMPO ALEGRE, 2018 (ANA MOREIRA, DORI NEGRO, JOCLÉCIO AZEVEDO, PEDRO PRAZERES, ANA ISABEL CASTRO, ROCIO DOMINGUEZ), [F] SUSANA NEVES

menos visível de tudo seja o diálogo que Sónia instala entre as co-criadoras performers, cuja participação não se esgota nos momentos ao vivo aqui já enunciados, mas em todo um processo de criação e escrita do guião, que antecipou o espectáculo e resultou depois num precioso objecto-livro escrito e construído todo artesanalmente, folha a folha, cosido à mão, página a página, letra a letra, que oferece uma outra forma de acesso à cosmologia de Sónia.

Joclécio Azevedo nasceu no Brasil em 1969, mas é em Portugal, no Porto, que nos anos 90 do século $\mathrm{xx}$ inicia um percurso na dança contemporânea, o qual o leva a assinar criações em nome próprio. Em 2001, Sónia Baptista é distinguida pelos extintos prémios do Ministério da Cultura, por revelação, relativo à primeira obra, Haikus. Apesar das radicais diferenças entre os dois e os seus referentes artísticos, ousaria situar ambos numa geração (com toda a ambiguidade que o termo contém) intermédia da dança portuguesa - surgidos já num período posterior às conquistas de liberdades artísticas empreendidas por uma primeira geração de dança nos anos 80/90 do século $\mathrm{xx}$, revolucionária no uso do experimentalismo e na recusa do corpo que se move sem porquê. Esta geração 


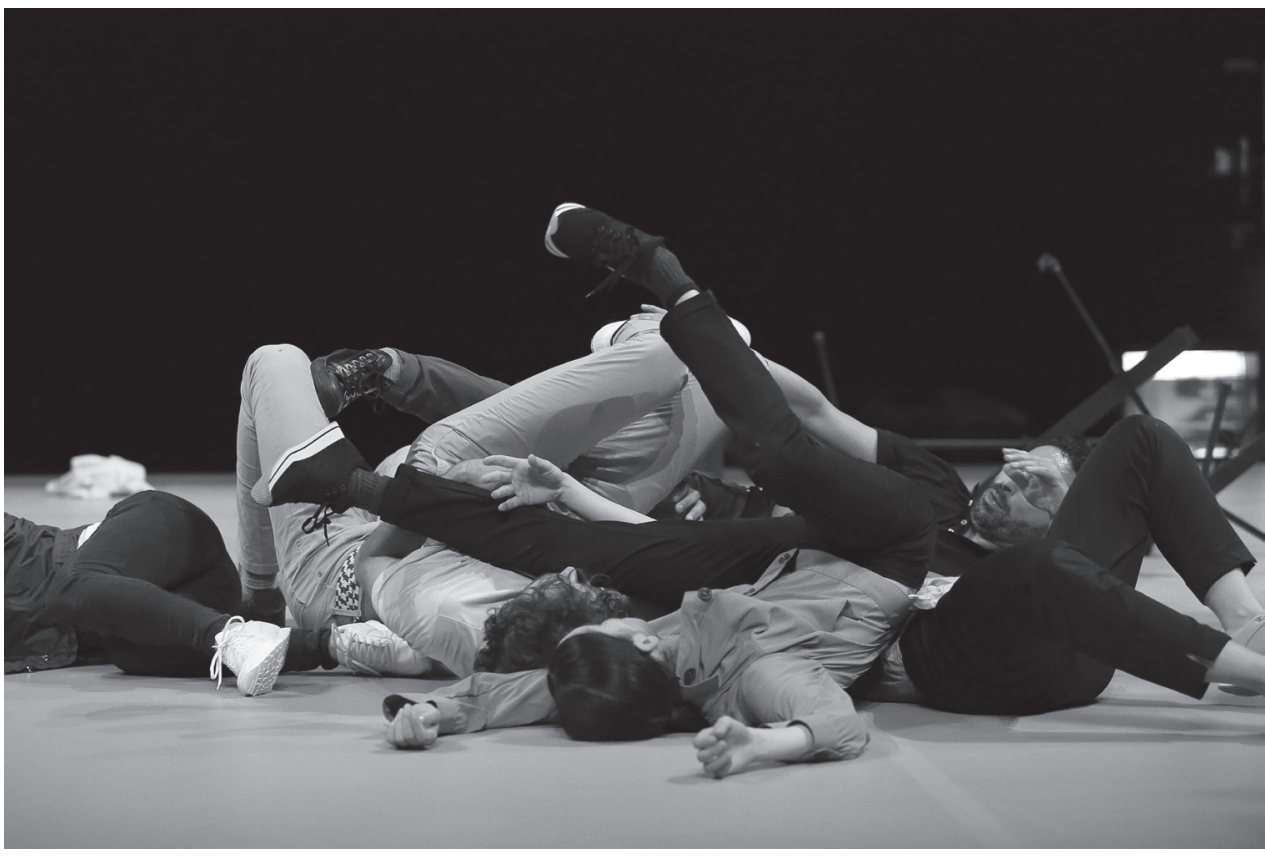

DOCUMENTÁRIO, DE JOCLÉCIO AZEVEDO, TEATRO MUNICIPAL DO PORTO - TEATRO CAMPO ALEGRE, 2018 (ANA MOREIRA, DORI NEGRO, JOCLÉCIO AZEVEDO, PEDRO PRAZERES, ANA ISABEL CASTRO, ROCIO DOMINGUEZ), [F] SUSANA NEVES

intermédia tem ainda pouca distância temporal desta primeira vaga para se afirmar parte de um movimento de renovação geracional. Quando chegam, as atenções ainda estão focadas nos pioneiros, que são hoje referências fundamentais nas possibilidades de criar a partir da dança, mas não se esgotando nesta. Estes autores da «geração intermédia», por outro lado, também não estão distantes o suficiente. Precisamos de mais tempo para identificar uma renovação de agentes de uma nova vaga, que integram a liberdade artística do que foi conquistado mas combinada com novas identidades, novos fôlegos criativos, como agora assistimos em nomes como, por exemplo, Marlene Monteiro Freitas, Victor Hugo Pontes, Lander Patrick e Jonas Lopes, João dos Santos Martins, Marco da Silva Ferreira, Cristina Planas Leitão... A vitalidade destes criadores de geração intermédia está na integridade das questões formuladas pelo espectáculo não conformada com a eficácia, situando-se num território amplo entre a dança e a performance de autoria portuguesa. Nesse lugar intermédio, identifico a substância do trabalho que desenvolvem: parte de uma ética artística e humana, que faz associar a todo o gesto criativo uma responsabilidade cívica e que defende valores, mas também os 
utiliza como recursos estilísticos nas próprias obras. E assim opera a dissolução da conformidade com as expectativas hoje vigentes no circuito comercial alternativo mainstream.

É aí que encontro uma comum mais-valia no trabalho de ambos, a partir de registos e identidades muito distintos. Ou seja, os discursos artísticos das novas gerações (surgidas na última década e meia) trazem uma consciência da pressão do mercado das artes performativas a que desejam corresponder (legitimamente, claro) e, de modo muito diverso, transportam a urgência de entrar em diálogo com este mercado, mesmo quando a procura se faz por rupturas, disrupções e a invenção delirante de um novo vocabulário, que é explorado nos limites e no virtuosismo do rigor físico.

No caso da geração intermédia, o que importa é o impulso, primeiro gerador artístico, e manter presente essa vitalidade primeira. $\mathrm{O}$ objecto performativo ao vivo, tende, pois, a concordar com a equação e problemáticas enunciadas, afirmando-se discreto e quase numa qualidade neutra da presença do corpo em cena, que assim opera num grau de redução o seu impacto de afectação e sedução do espectador. Este é em particular um traço distintivo de Joclécio Azevedo e de Documentário. Esta opção situa-o numa certa margem e radicalidade: no caso de Joclécio, por via de operações de exploração de movimento que se sustentam no trabalho relacional entre todos os intérpretes e num desprendimento face à procura da eficácia de inscrição de cada gesto. $\mathrm{O}$ acontecimento do momento ao vivo é mais testemunha dessa preocupação com o instalar em cena de uma dinâmica problematizadora das atenções do espectador, de activação discreta dos materiais antes considerados «arquivo», e exigente da disponibilidade para o encontro que se dá ao vivo, que se distrai de forma intencional de qualquer facilitação da recepção e/ou comunicação. Aliás, uma das qualidades de Documentário, de Joclécio, consiste precisamente no pôr em causa essa relação directa entre significado e significante. Assim, ao destruí-la, ataca os próprios alicerces em que comummente se dá a comunicação artística. Esta formulação facilmente é entendida como «falha» do acto comunicativo e «falha» do espectáculo como máquina de desejo. Na realidade, o que Joclécio faz é resistir à tentação de ceder às modalidades do facilitismo, propondo a exigência de implicação de quem assiste para procurar formas alternativas de articular a relação de construção de significados que não meramente por puro prazer e excitação dos sentidos ou exibição de um virtuosismo físico. 


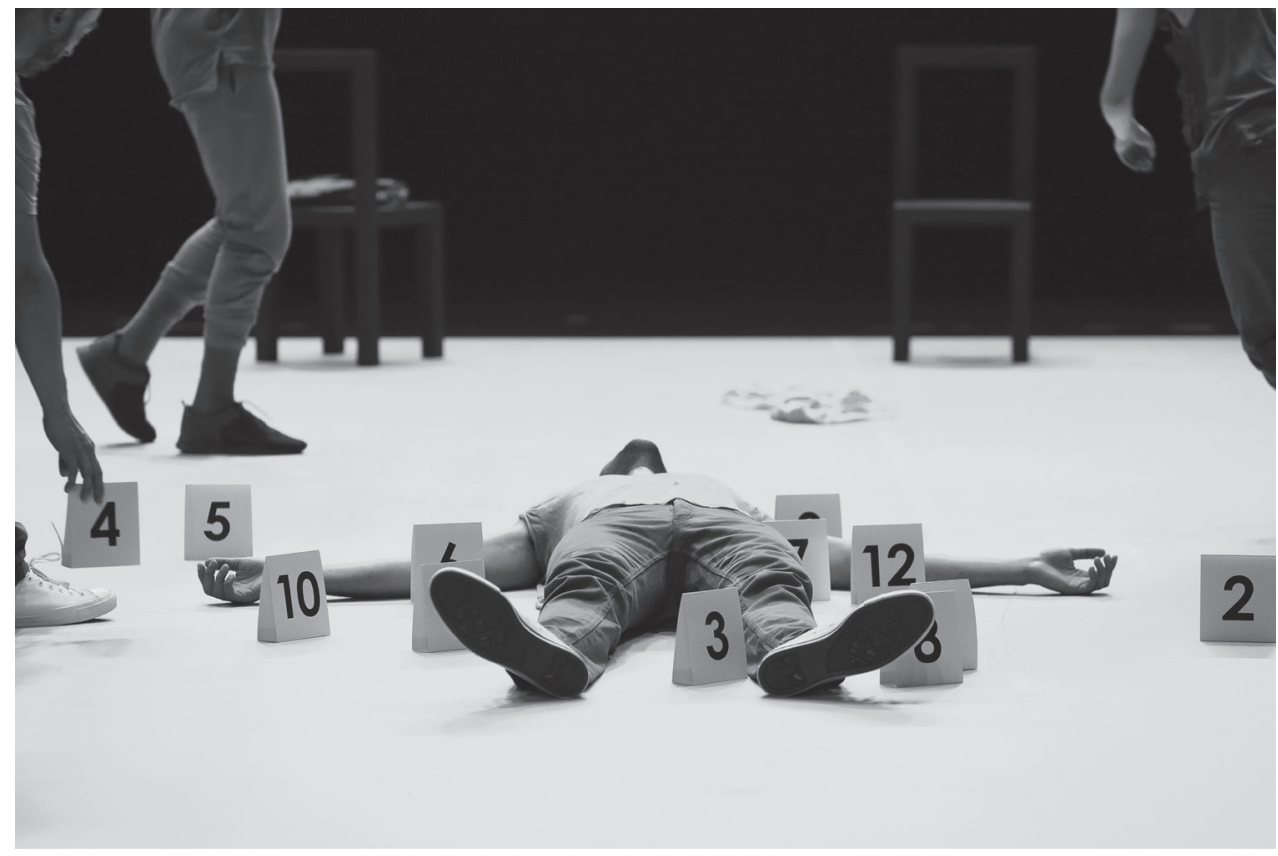

DOCUMENTÁRIO, DE JOCLÉCIO AZEVEDO, TEATRO MUNICIPAL DO PORTO - TEATRO CAMPO ALEGRE, 2018, [F] SUSANA NEVES

Os corpos, em Documentário, têm uma qualidade correspondente aos próprios objectos cénicos - mesas, cadeiras, tripés, microfones... Todos eles surgem como esboços que se vão insinuando, mas não chegam nunca a constituir-se como materialização completa do que enunciam nem sequer cumprem a sua função e utilidade. Como um traço, como um delinear das linhas, esvaziadas da sua constituição material, eles parecem ter um valor equivalente ao gesto e movimento, repetitivo e efémero, dos intérpretes. Inscrevem o desaparecimento. Esta dança é permanente dissolução, reafirmada em dessincronia pelo trabalho cénico do artista plástico Paulo Mendes (com as montagens rápidas de cenas de filmes ou publicidade em quatro ecrãs de televisão, ou o chão verde que delimita o espaço cénico que é um chroma de estúdio de televisão, ou seja, a sua existência anuncia-se entre o nada e a possibilidade de tudo o que ali se possa evocar) e a criação de música e som de Pedro Tudela.

Neste sentido, a problematização artística, formal, linguística, documental, política, que Joclécio propõe, está mais próxima de um discurso das artes visuais, mesmo se o seu contexto de apresentação é o palco. Aqui não se trata de uma deslocação ou descontextualização, trata-se simplesmente de activar um estado de consciência da presença, reinscrevendo 
a naturalidade do estar e do movimento, gerados num desprendimento que revaloriza uma partilha em tempo real. De certo modo, Joclécio desorganiza o público e as suas expectativas, mas por via de operações de redução, que pedem uma maior atenção e sugerem a renovação crítica do treino do olhar para trabalhar e se focar no detalhe.

De modo paralelo às permanentes e bruscas interrupções e repetições propostas pela montagem de vídeo, reproduzidas pelos ecrãs de televisão (propostos por Paulo Mendes), ou pela manipulação sonora (proposta por Pedro Tudela), Documentário gera o colapso. Mas de forma radicalmente diferente dessas colisões cinematográficas. Esta crise não se dá por via de colisões aparatosas, encontros voluptuosos sexuais, desastres ou assassinatos, como as imagens sugerem, mas antes numa pulsação intermédia, interna, suscitando os opostos - ou suscitando simultaneamente, em permanente transição, a coisa/gesto e a sua negação -, nomeadamente de discursos vigentes, denunciando as suas contradições.

Este enunciado do contraditório surge logo no confronto, produtivo, entre o que é visto no espectáculo ao vivo e o trabalho de reflexão, debate, discussão, pesquisa, documentação... desenvolvido de forma prolongada no tempo e que também passou por uma publicação que documenta todo esse percurso. Nesse livro, Joclécio traça o mapa complexo das questões que o movem e as várias conversas e encontros que foram informando a pesquisa, que extravasa uma ideia contemporânea convencionada de processo criativo. Ali fica clara a coerência entre a questão problematizada e os media a que recorre para lhe dar forma - manipulação de arquivos visuais e sonoros, laboratórios de pesquisa, sempre reformulando a ideia de trabalho, recolha de múltiplas contribuições em livro, workshops, debates e espectáculo. Este projecto nasce da convicção de que «vivemos num processo de montagem e de edição permanente da realidade», como me disse Joclécio na conversa que partilhámos para a publicação que acompanha Documentário. O livro testemunha como a construção vocabular do corpo é geradora «de desintegração de protocolos de comunicação e de produção do discurso». Ele situa a voz que se escuta no início do espectáculo, a do filósofo Franco Berardi, e a sua noção de «menos-valia» como variação mais agressiva da «mais-valia» do sistema capitalista, em que associa a crise financeira de 2008 à ideia de aniquilação. É Berardi também que fala sobre a ideia do nada, da aniquilação, das coisas que se transformam noutras coisas - as primeiras residências de criação deste projecto passaram pela escuta da conferência Performativity and nothingness, de 2014, de Berardi. É também disto 
que se trata em Documentário. Como quando Joclécio, nessa conversa, interroga: «Quando alguém morre, o que morre exactamente? O corpo transforma-se noutras matérias. Há imagens que persistem na memória dos que ficam vivos.» É nessa delicada permanência de algo no equilíbrio frágil entre o desaparecimento e a transformação que Documentário se dá. 